\title{
Journal of Vascular Research and the Internet
}

It is no exaggeration to observe that the arrival of the Internet is causing a revolution in the field of scientific publishing. One result is that most leading journals are now available for subscribers as net versions for a modest extra charge, and the Journal of Vascular Research is no exception: use http://www.karger.ch/journals/jvr/ jvr_jh.htm. However, the ability for instant viewing of the literature from our desks is not the only advantage presented by the Internet for scientific publication. Many other possibilities are becoming available, and it is the intention of the editors and publishers of the Journal of Vascular Research that full use should be made of these. In this respect, our overriding aim is to combine the flexibility of cyberspace availability with the permanence and solidity of paper publication.

As a particular example, readers will have noticed that the previous number of Journal of Vascular Research indexed an 'electronics supplement' [J Vasc Res 1988; 35(suppl 3)] which consists of abstracts in the vascular field which were presented at the INABIS98 Internet World Congress of Biomedical Science held on the Internet, 7-16 December (see http://www.mcmaster.ca/ inabis98/index.html). These abstracts can be viewed by all (subscribers and nonsubscribers alike) on the JVR website indicated above, and will be permanently avail- able. The advantage of this publication is that references to these abstracts can be made in the normal way [e.g. J Vasc Res 1998;35(suppl 3):xx]. In addition to this record of the vascular aspects of INABIS98, a Meeting Report of the relevant sections will be published in the next number of the Journal of Vascular Research, as well as a shortened version of one of the Keynote Lectures by Dr. A.W. Cowley ('The Emergence of Physiological Genomics').

Other innovations which will be introduced over the next year or so include the following. (1) Internet publication of abstracts immediately on acceptance, providing that these are submitted on disk. (2) Internet submission of manuscripts and distribution to referees. (3) Immediate publication of selected manuscripts on the Internet following the normal review process, with the opportunity for Internet discussion. Subscribers would be alerted to these selected manuscripts via e-mail. At the discretion of the editors, an edited version of this discussion would then be printed together with the published paper.

It is the editors' hope that subscribers, readers and contributors to the Journal of Vascular Research will find this approach to be a constructive use of the Internet, by allowing increased scientific interaction without any lowering of scientific standards. 